\title{
Evaluation of landfill site choice using AHP and GIS case study: Oum Azza, morocco
}

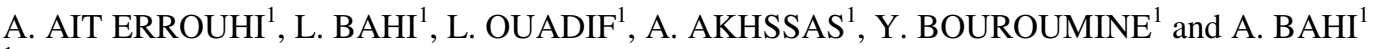 \\ ${ }^{1}$ Laboratory of Applied Geophysics, Geotechnics and Geology of Engineers and Environment, Mohammadia \\ School of Engineers, Mohammed V University, Rabat, Morocco
}

\begin{abstract}
The amount of household waste produced by the mainly urban population in Morocco continues to increase year after year. Morocco is thus confronted with the problems of storage and disposal of this waste, which are composed largely of organic matter, bio-waste. In the recent past, these wastes have been buried in wild dumps or in old quarries located in areas close to urban centers without any treatment or control. This can constitute significant risks both for public health and the environment and for the future of the socio-economic activities of the country. For which evaluating municipal landfills is vital due to the importance of health and environmental issues and the possibility of contravening environmental and engineering criteria and principles. The present research is conducted using new techniques of approach among others, the analytical hierarchy process AHP, which will allow us to weight and combine all criteria and to classify their respective weights, as well as the use of GIS which will contribute to the evaluation of these criteria in order to determine whether the choice of the current site according to the results of our study meets the requirements of a controlled landfill respecting the environment.
\end{abstract}

\section{Introduction}

Waste management solids remained debatable up to now in the near total of the countries of the world. The capital concern relates to the evacuation of the refuse produced by the households with an aim of improving cleanliness and protection of public health. This waste finishes for most of the time in waste grounds. Nearly $98 \%$ of cities in developing countries have only not controlled discharges which, in the averages and small towns summarize simple wild dumps into cubes in which waste is often burned for the dry periods to reduce the quantity [1]. The access to these sites is controlled little and there exists an important informal sector of recovery involving health risks and embarrassments of exploitation. It should be noted that land filling is the most widespread waste treatment solution in the world but also the least expensive. However, while this practice is relatively controlled and restraint in western countries, it is still a problem in developing countries due to lack of controls, inadequate or nonfunctional arrangements and funding difficulties.

In Morocco, in order to face the problem of wild dumps and their eminent character, land filling is certainly a good choice, but this option is far from being ecologically sustainable where the waste is very wet and very rich in organic matter and generate large volumes of leachate. Like the majority of the provinces of the Kingdom, the province of Temara Sekhirat includes a controlled landfill in Oum Azza, which covers an area of 110 hectares and receives 1,800 tons of solid household and similar waste. This landfill raises the dissatisfaction of the neighboring population by obvious nuisances such as odors, groundwater pollution and road degradation due to truck passages.

The objective of our study is to evaluate the site using the geographic information system GIS, which plays a crucial role in planning, to see if the landfill meets legislative requirements and respects the environment, Possibility of identifying other better sites that could well house the latter.

GIS can also play a key role in maintaining data to facilitate collection operations, customer service, analysis of optimal locations for transfer stations, planning of the route for the transport of waste to transfer stations and stations transferring to 
landfills, and long-term landfill monitoring [2], As it can be a decision-making tool, simplifying the search for sites suitable for a particular use because of its ability to extract spatial characteristics and classification. The process of site selection is complicated, hence the need to integrate several decision support tools such as multi-criteria evaluation (MCE) for optimal selection [3].

Among MCE techniques, the Analytic Hierarchy Process (AHP) is one of the most common analytical techniques for complex decision-making problems and is widely used because of its agility and easy to use. It helps decision-makers discern which is best suited to their goal and problem design. It provides a comprehensive and rational framework for structuring a decision problem, representing and quantifying its elements to link these elements to the overall objectives and to evaluate alternative solutions [2]. To that end, a hierarchical tree is created: the decision-making hierarchy tree represents the decision strategy graphically; it uses a multi-level hierarchical structure of objectives, criteria, sub-criteria, and alternatives. The pertinent data are derived by using a set of pairwise comparisons. These comparisons are used to obtain the weights of importance of the decision criteria, and the relative performance measures of the alternatives in terms of each individual decision criterion [4].

The evaluation of this waste disposal site is a complex process because it requires considerable expertise in various social and environmental fields, such as soil science, distance to homes, engineering, hydrogeology, and topography, Land use, leaching of contaminants, sociology and economics [5].

Therefore, the site selection of a solid waste landfill must also involve the processing of a significant amount of spatial data, regulations and acceptance criteria, as well as an effective correlation between them. Some promising approaches to landfill assessment have been discussed by Gebhardt [6], Swallow [7], Chen [8] and Sasao [9].

The present study's purpose is to develop a methodology to evaluate the landfill site choice using AHP and GIS for the study area Oum Azza, Morocco.

\section{Study area}

The region of Rabat, Sale, Zemmour and Zaers (RSZZ) is located in the north-west of the country, covering an area of $9,580 \mathrm{~km} 2$ and 2,134,533 inhabitants (RGPH 2014). It is bounded on the north by the region of Rharb-Cherrda-Beni hssen, on the east by the region of Fes-Meknes, on the south by the region of Chaouiya Ouedrigha and on the West by the Atlantic Ocean.

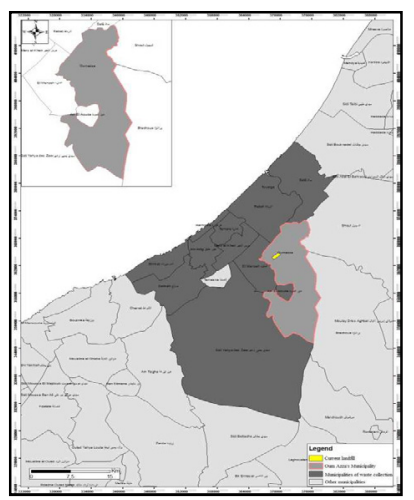

Fig. 1: Location of study area

This region is characterized by relatively favorable climatic conditions. The geographical distribution of temperatures and precipitation is influenced by the latitude, distance from the ocean and altitude.

In terms of temperature, three different thermal domains are categorized: an oceanic domain in the coastal zone, a semi-continental domain (Tifelt, Roummani and Khemisset) and a middle mountain area (Oulmes area). In addition, the average temperature varies between 17 and $18^{\circ}$ C. In terms of rainfall, there are two regimes according to altitude: Plains and plateaus with a rainfall of $500 \mathrm{~mm} /$ year (Rabat-Tifelt, Tiddas), the mid-mountain zone with a rainfall of $660 \mathrm{~mm} /$ Year (Oulmes).

The RSZZ region houses a landfill in the rural commune of Oum Azza on the Ain Aouda plateau. It is located between Wadi Akrach to the west and the reservoir of the Sidi Mohamed Ben Abdellah dam in the east, with elevation between 160 and 200 NGM. It receives household and similar waste from 13 communes: Rabat, Sale, Bouknadel, Temara, Skhirate, Harhoura, Ain Aouda, Mers Kheir, Al Manzeh, Ain Attig, Sebbah, S.Yahya Zaers and Oum Azza, and serves a population of 980,000 inhabitants. Its area is about 111 ha.

\section{Methods and materials}

\subsection{Geographic Information System}

Available information on geology, hydrogeology, hydrology, soil, climatology and eco-sociology has been assembled and compiled in digital form. Several source maps helped to prepare the geographic database. These maps were at different scales and included different types and quantities of information. Thus, several maps have been produced, namely: topographic maps of the region Rabat Kenitra, especially topographic map of the city of Temara with a scale of $1 / 50000$, municipality of Rommani with a scale of $1 / 50000$ and rural communities of Larba't As-Sehoul, Sidi Bettach and Sidi Bouqnadel with a scale of 
1/50000, geologic map of the study area with a scale of $1 / 100000$ and World Imagery from GIS. All these data allowed the preparation of a database in the information system with spatial reference of the region of Rabat Sale and Kenitra.

The allocated model to evaluate the current site of the Oum Azza landfill for the storage of waste, consists of a compilation of relative geographical data in GIS as a decision support system. In each version, various localization techniques have allowed the creation of basic spatial documents in raster or vector format [10 and $11]$.

\subsection{Analytic Hierarchy Process AHP}

Analytic hierarchy process (AHP) is one of the most popular analytical techniques for complex decision making problems and is widely used due to its flexibility and easy to use. An AHP hierarchy can have many levels to characterize a decision condition. The selected factors governing the suitability of the site are weighted using this analytical method which is aided by pairwise comparison matrix that uses a scale of relative importance [12]. Once the weights are determined, the AHP calculates the relation between the weights of criteria and then calculates the total value of each option based on the weight obtained [13]. To make a decision in an organized way to generate priorities we need to decompose the decision into the following steps:

1- To define the problem and determine the kind of knowledge sought.

2- To structure the decision hierarchy from the top with the goal of the decision, then the objectives from a broad perspective, through the intermediate levels (criteria on which subsequent elements depend) to the lowest level.

3- Construct a set of pairwise comparison matrices. Each element in an upper level is used to compare the elements in the level immediately below with respect to it. The scale for comparison consists of values ranging from 1 to 9 which describe the intensity of importance, by which a value of 1 expresses equal importance and a value of 9 is given to those factors having an extreme importance over another factor.

4- Use the priorities obtained from the comparisons to weigh the priorities in the level immediately below. Do this for every element. Then for each element in the level below add its weighed values and obtain its overall or global priority [14].

In AHP, at first the decision problem was decomposed into simpler decision problems to form a decision hierarchy. Then, pairwise comparisons were done. Pairwise comparison method is mainly used because it is hierarchical, statistical and easy to use. It is a precise method with high credibility.

In the second part of our study, after the maps obtained using GIS, AHP will allow us to evaluate the current landfill site based on four criteria: economic impact, environmental impact, social impact and technical impact. In order to identify the criterion to be taken into consideration to ensure that the landfill meets legislative and environmental requirements. To do this we have developed an algorithm that will help us to make these calculations for $\mathrm{n}$ criteria.

The matrix of the ratios of all weights

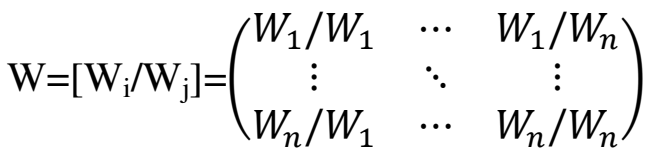

With $\mathrm{n}$ : the number of compared alternative $\mathrm{W}_{1}, \mathrm{Wn}$ : their current weights

The matrix of pairwise comparisons $A=\left[a_{i j}\right]$ represents the intensities of the stakeholders preference between individual pairs of alternatives. They are usually chosen from a given scale $(1 / 9,1 / 7, \ldots, 7,9)$. Given $\mathrm{n}$ alternatives, a decision maker compares pairs of alternatives for all the possible pairs, and a comparison matrix $\mathrm{A}$ is obtained, where the element aij shows the preference weight of $\mathrm{Ai}$ obtained by comparison with $\mathrm{Aj}$ [15].

$\mathrm{A}=\left[\mathrm{a}_{\mathrm{ij}}\right]=\left[\begin{array}{ccc}1 & a_{1 j} & a_{1 n} \\ 1 / a_{1 j} & 1 & a_{i n} \\ 1 / a_{1 n} & 1 / a_{i n} & 1\end{array}\right]$

The $\mathrm{a}_{\mathrm{ij}}$ elements estimate the ratios $\mathrm{w}_{\mathrm{i}} / \mathrm{w}_{\mathrm{j}}$ where $\mathrm{w}$ is the vector of current weights of the alternative.

$$
A w=\lambda_{\max } \cdot w(2)
$$

With $\lambda_{\max }$ : eigenvalue, [16].

The consistency index (CI) as follows:

$$
C I=\frac{\lambda_{\max }-n}{n-1}
$$

Consistency Ratio (CR) to measure how consistent the judgements have been relative to large samples of purely random judgements.

If $\mathrm{CR} \leq 0.1$ is true for matrix $\mathrm{A}$, the assessments of the relative importance of the criteria are considered as acceptable.

If the CR is much in excess of 0.1 the judgements are untrustworthy because they are too close for 
comfort to randomness and we need to consider revising our subjective judgments (the exercise is valueless or must be repeated). For Saaty [15], defined the consistency ratio $(\mathrm{CR})$ as :

$$
C R=\frac{C I}{R I}
$$

With RI is the random index: consistency index for the $n$ row matrixes of randomly generated comparisons in pairs.

$$
R I=\frac{\lambda_{\max }-n}{n-1}
$$

With $\bar{\lambda}_{\max },[17]$ :

$$
\bar{\lambda}_{\max }=(2.7699 * n)-4.3513
$$

Figure 2 shows the algorithm that we have done to calculate the weight of criteria.

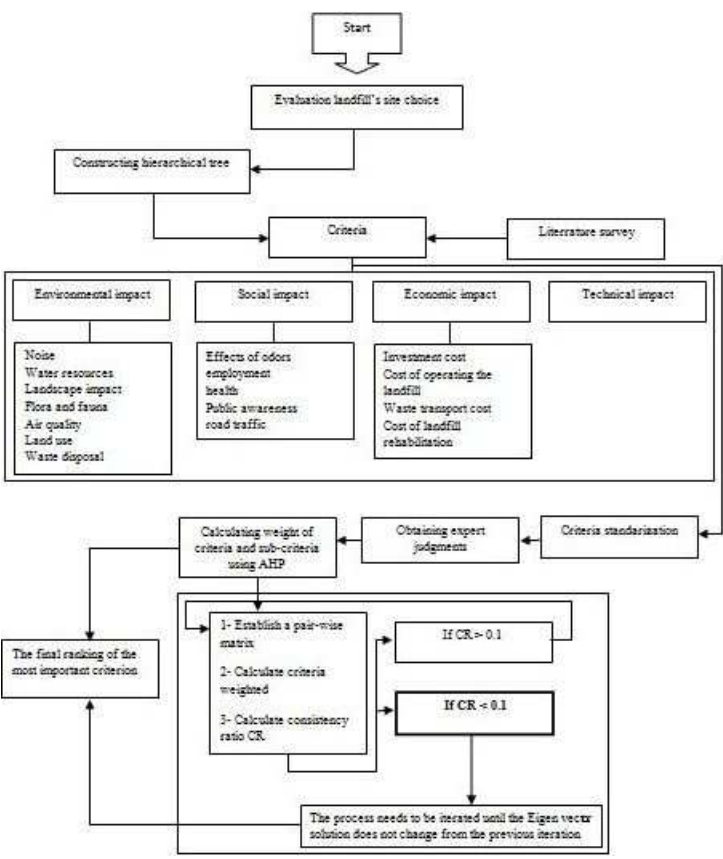

Fig.2: The flow chart illustrating the methodology used for evaluating the most important criteria

\section{Results and discussion}

After the digitization of the collected data, it was possible to extract the main data relating to the study area of Oum Azza. We observe at the vegetation cover, the majority of land is occupied by food crops, which are largely self-consumed by peasants and the local population. Also, Trees and shrubs are mostly identified along hedges along roads and certain plots (figure 4 ). As far as the infrastructure of the region is concerned, there is the Bouregreg complex, including the dam and the reservoir of Sidi Mohamed Ben Abdellah, the roadways P 22 and S 202, the Rabat bypass highway which has just been put into service and which crosses the town of Rommani, High and medium voltage lines, and the site of Sidi Mohammed and of Sidi M'bark belong to the National cultural heritage (holy places) (figure 3). (Figure 5), shows that the municipality of Oum Azza is crossed by several permanent and nonpermanent watercourses. This municipality belongs to the watershed of the Bou-Regreg, the rainfall on the plateau is directed to the east, towards the wadi Korifla and the Sidi Mohamed Ben Abdellah reservoir, to the west, to the wadi Akrach. Wadi Akrach is a direct tributary of the Oued BouRegreg. It is not the same for the wadi Korifla which first conflates to the Oued Mechraa. The wadis draining the plateau, and particularly the Hachichia river, are relatively little used for

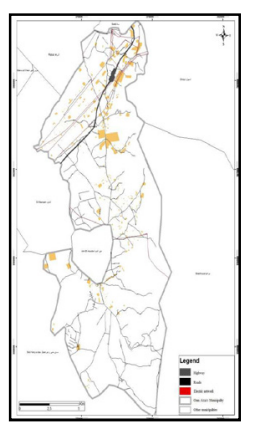

Fig. 3:

Infrastructure map of Oum Azza

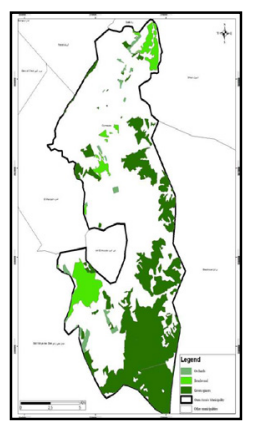

Fig. 4: Map of vegetation cover of Oum Azza

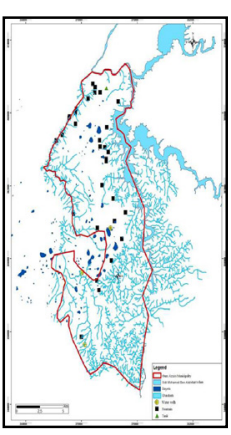

Fig. 5:

Hydrological map of Oum Azza irrigation of crops. The same is true for daya.

In order to evaluate the current site of the landfill, the table 1 shows a list of exclusion criteria on which we based ourselves for the rest of our study.

Table. 1: List of exclusion criteria and areas

\begin{tabular}{|c|c|}
\hline Exclusion criteria & Exclusion area \\
\hline Living areas & $500 \mathrm{~m}$ \\
\hline Roads & $300 \mathrm{~m}$ \\
Highway & $500 \mathrm{~m}$ \\
\hline Electrical networks & $200 \mathrm{~m}$ \\
\hline Cemeteries and & $500 \mathrm{~m}$ \\
religious institutions & \\
\hline Green spaces & $500 \mathrm{~m}$ \\
Protected areas & $500 \mathrm{~m}$ \\
Agricultural areas & $300 \mathrm{~m}$ \\
Forests & $300 \mathrm{~m}$ \\
Natural parks & $1000 \mathrm{~m}$ \\
\hline Oueds, chaabats & $500 \mathrm{~m}$ \\
Fountains & $500 \mathrm{~m}$ \\
\hline Water resources & $400 \mathrm{~m}$ \\
\hline
\end{tabular}


From the table 1, we have inserted the corresponding exclusion areas for each exclusion criterion in our GIS database. The software allowed us to conclude that the current site of the Oum Azza landfill does not meet certain exclusion criteria (figures 6,7 and 8).
Fig.6 : Map showing the exclusion criteria of living areas

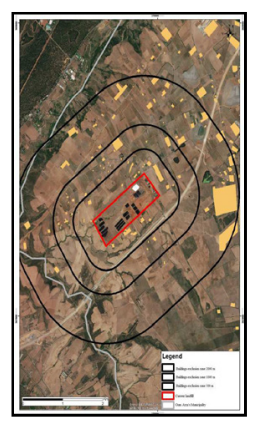

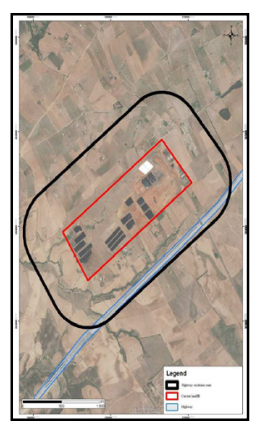

Fig.7 : Map showing the exclusion criteria of the highway

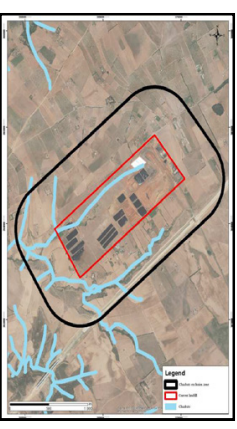

Fig.8 : Map showing the exclusion criteria of water resources
When assessing the current landfill site, we note that the current site does not meet certain exclusion criteria; as has been shown in the preceding figures, for the (figure 6) concerning living areas; it can be seen that the exclusion area of $500 \mathrm{~m}$ was not taken into account and there are indeed households, also for (figure 8) shows that the criterion of exclusion for water resources at a distance of $200 \mathrm{~m}$ was not respected, which could harm the health of the population and the same case for the criterion of exclusion of the highway to an exclusion area of $500 \mathrm{~m}$ (figure 7).

In the present descriptive-analytic study, to determine the weight of each of the criteria, economic, environment, social and technical impact, we used the method of decision-making (AHP). These criteria will be calculated by the application that we have developed. Then the criteria, evaluation options of the Oum Azza landfill will be ranked and prioritized.

Table. 2: Pairwise comparison matrix of the main criteria

Environment (En), social (S), economical (Eco), technical (T).

\begin{tabular}{|c|c|c|c|c|c|}
\hline Criteria & En & S & Eco & T & Weight \\
\hline En & 1 & 2 & 9 & 5 & 0.518 \\
\hline S & 0.5 & 1 & 9 & 3 & 0.316 \\
\hline Eco & 0.11 & 0.11 & 1 & 0.2 & 0.038 \\
\hline T & 0.2 & 0.33 & 5 & 1 & 0.128 \\
\hline
\end{tabular}

Table. 3: Pairwise comparison matrix for the sub-criteria with respect to environment

Noise (N), water resources (WR), landscape impact (LI), flora and fauna (F), air quality (A), land use (LU), waste disposal (WD).

\begin{tabular}{|c|c|c|c|c|c|c|c|c|}
\hline En & N & WR & LI & F & A & LU & WD & Weight \\
\hline N & 1 & 0.11 & 3 & 0,33 & 0,11 & 0,14 & 3 & 0,043 \\
\hline WR & 9 & 1 & 7 & 3 & 0,33 & 2 & 7 & 0,227 \\
\hline LI & 0,3 & 0,14 & 1 & 0,2 & 0,11 & 0,2 & 2 & 0,029 \\
\hline F & 3 & 0,33 & 5 & 1 & 0,2 & 0,33 & 5 & 0,092 \\
\hline A & 9 & 3 & 9 & 5 & 1 & 5 & 9 & 0,425 \\
\hline LU & 7 & 0,5 & 5 & 3 & 0,2 & 1 & 5 & 0,158 \\
\hline WD & 0,3 & 0,14 & 0,5 & 0,2 & 0,11 & 0,2 & 1 & 0,024 \\
\hline
\end{tabular}

Table. 4: Pairwise comparison matrix for the sub-criteria with respect to social

Effects of odors (EO), employment (E), health $(\mathrm{H})$, public awareness $(\mathrm{P})$, road traffic $(\mathrm{R})$.

\begin{tabular}{|c|c|c|c|c|c|c|}
\hline S & E & EO & H & P & R & Weight \\
\hline E & 1 & 3 & 0.2 & 2 & 5 & 0.173 \\
\hline EO & 0.33 & 1 & 0.11 & 0.2 & 0.5 & 0.04 \\
\hline H & 5 & 9 & 1 & 7 & 9 & 0.6 \\
\hline P & 0.5 & 5 & 0.14 & 1 & 5 & 0.139 \\
\hline R & 0.2 & 2 & 0.11 & 0.2 & 1 & 0.048 \\
\hline
\end{tabular}

Table. 5: Pairwise comparison matrix for the sub-criteria with respect to economy

Investment cost (IC), cost of operating the landfill (CO), waste transport cost (WT), cost of landfill rehabilitation (CR).

\begin{tabular}{|c|c|c|c|c|c|}
\hline Eco & IC & CO & WT & CR & Weight \\
\hline IC & 1 & 0.14 & 0.125 & 0.33 & 0.048 \\
\hline CO & 7 & 1 & 0.5 & 5 & 0.367 \\
\hline WT & 8 & 2 & 1 & 3 & 0.467 \\
\hline CR & 3 & 0.2 & 0.33 & 1 & 0.118 \\
\hline
\end{tabular}

Table. 6: final weights

\begin{tabular}{|c|c|c|c|c|}
\hline \multicolumn{2}{|c|}{ Criteria } & \multicolumn{2}{|c|}{ Sub-criteria } & \multirow{2}{*}{$\begin{array}{c}\text { Final } \\
\text { weight }\end{array}$} \\
\hline Description & Weight & Description & Weight & \\
\hline \multirow{3}{*}{ 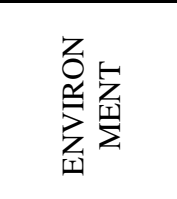 } & \multirow{3}{*}{$51.8 \%$} & Noise & $4.3 \%$ & $2.22 \%$ \\
\hline & & $\begin{array}{l}\text { Water } \\
\text { resources }\end{array}$ & $22.7 \%$ & $11.7 \%$ \\
\hline & & $\begin{array}{l}\text { Landscape } \\
\text { impact }\end{array}$ & $2.9 \%$ & $1.5 \%$ \\
\hline
\end{tabular}




\begin{tabular}{|c|c|c|c|c|}
\hline \multicolumn{2}{|c|}{ Criteria } & \multicolumn{2}{|c|}{ Sub-criteria } & \multirow{2}{*}{$\begin{array}{c}\text { Final } \\
\text { weight }\end{array}$} \\
\hline Description & Weight & Description & Weight & \\
\hline & & $\begin{array}{l}\text { Flora and } \\
\text { fauna }\end{array}$ & $9.2 \%$ & $4.76 \%$ \\
\hline & & Air quality & $42.5 \%$ & $22.02 \%$ \\
\hline & & Land use & $15.8 \%$ & $8.18 \%$ \\
\hline & & $\begin{array}{l}\text { Waste } \\
\text { disposal }\end{array}$ & $2.4 \%$ & $1.24 \%$ \\
\hline \multirow{5}{*}{ 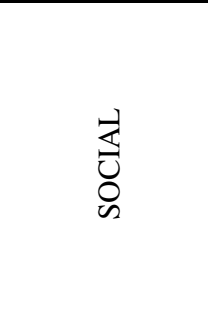 } & \multirow{5}{*}{$31.6 \%$} & $\begin{array}{ll}\begin{array}{l}\text { Effects of } \\
\text { odors }\end{array} \\
\end{array}$ & $4 \%$ & $1.26 \%$ \\
\hline & & Employment & $17.3 \%$ & $5.4 \%$ \\
\hline & & Health & $60 \%$ & $18.9 \%$ \\
\hline & & \begin{tabular}{|l|} 
Public \\
awareness
\end{tabular} & $13.9 \%$ & $4.39 \%$ \\
\hline & & Road traffic & $4.8 \%$ & $1.51 \%$ \\
\hline \multirow{4}{*}{ 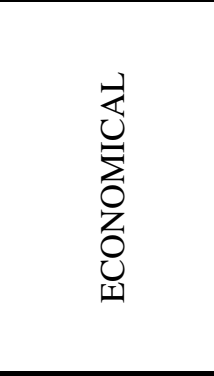 } & \multirow{4}{*}{$3.8 \%$} & $\begin{array}{l}\text { Investment } \\
\text { cost }\end{array}$ & $4.8 \%$ & $0.18 \%$ \\
\hline & & $\begin{array}{l}\text { Cost of } \\
\text { operating the } \\
\text { landfill }\end{array}$ & $36.7 \%$ & $1.39 \%$ \\
\hline & & $\begin{array}{l}\text { Waste } \\
\text { transport cost }\end{array}$ & $46.7 \%$ & $1.77 \%$ \\
\hline & & $\begin{array}{l}\text { Cost of } \\
\text { landfill } \\
\text { rehabilitation }\end{array}$ & $11.8 \%$ & $0.44 \%$ \\
\hline TECHNICAL & $12.8 \%$ & - & - & $12.8 \%$ \\
\hline
\end{tabular}

From tables 2, 3, 4 and 5, the CR obtained for the assessment of the current discharge site for each criterion and sub-criteria is 0.042, 0.074, 0.086 and 0.055 respectively. The consistency ratios are less than 0.1 indicating constant judgment and a reasonable level of consistency. According to the results of table 6 , it was concluded that the most important criterion is the environment with a weight of 0.581 , followed by the social and technical criteria which had as weights 0.316 and 0.128 respectively, on the other hand the economic criterion is ranked as the least important with 0.038 . At the level of sub-criteria we distinguish that air quality is more vulnerable with a weight of 0.220 and that the least vulnerable is the investment cost with a weight of 0.018 , given the region, where the landfill site is located, is coastal, it undergoes a seabreeze phenomenon, the latter during the day, the earth absorbs the heat emitted by the sun quickly and heats the air above it. On the other hand, the solar radiation on the sea is absorbed more slowly because of the higher thermal capacity of the latter. During the night, the earth cools faster than the sea, because of their difference in thermal capacity (the earth accumulates less heat from the sun than the sea, it cools faster at night), and inverse phenomenon occurs: the air above the earth is colder than that above the sea, which generates the spread of harmful odors from the landfill that detract the air quality which causes the dissatisfaction of the neighboring population.

Given that most of the criteria considered in this study may not have been considered in the selection of the current landfill site, this site is vulnerable and inhibited to be located in this area. The criteria considered in this study should be taken into account by decision makers to assess existing landfills and select the most suitable sites for future landfills. In addition, buffer zone distances for the above criteria should be established in the selection of future sites and maintained thereafter to avoid undesirable environmental impacts. In addition, the tool used in this study provides critical support to the decision-making process.

\section{Conclusion}

The present study studies the evaluation of the current site of the Oum Azza on the basis of different criteria. The results highlight the importance of multicriteria decision analysis to avoid vulnerability to the landfill and GIS environment that requires the collection of data from different sources with different formats to create a database unified. Thus, GIS data should be updated frequently to reflect the current situation in the study area. The criteria used in this study should be taken into account by decision makers in order to carry out evaluation studies at different existing landfill sites and to select the most suitable sites for future landfills.

\section{References}

[1] http://www.plateforme-re-sources.org/wpcontent/uploads/2015/10/08-FS-Decharge.pdf http://ma.chm-cbd.net/rabat-sale kenitra/region/monographie-de-la-region-rabat$\underline{\text { sale-kenitra }}$

[2] B. Kaoutar, B. Lahcen A Decision Support Approach for Optimized Sitting Of Municipal Solid Waste Landfill Case Study Tangier Morocco, International Journal of Engineering Research and Applications, Vol 2, Issue 6, pp 1676-1684, (2012).

[3] M. Oyinloye, J. Fasakin, Geographical information system (GIS) for sitting and management of solid waste disposal in Akure, 
Nigeria, Academia Journal of Scientific Research, Vol 1, pp 090-103, (2013).

[4] E. Triantaphyllou, Stuart H. Mann, Using the analytic hierarchy process for decision making in engineering applications: some challenges, International Journal of Industrial Engineering: Applications and Practice, Vol 2, pp 35-44, (1995).

[5] V. Sumathi, U. Natesan and C. Sarkar, GISbased approach for optimized siting of municipal solid waste landfill, ELSEVIER Waste Management, Vol 28, pp 2146-2160, (2008).

[6] K. Gebhardt, J. Jankowski, Preliminary landfill siting and related analysis using simple modeling techniques, Journal of Engineering Geology, Vol 23, pp 291-306, (1987).

[7] S.K. Swallow, J.J. Opaluch, T.F. Weaver, Siting noxious facilities: an approach that integrates technical, economics, and political consideration. Land Economics, Vol 68 (3), pp 283-301, (1992).

[8] W.Y. Chen, J.J. Kao, Fuzzy drastic for landfill siting. In: Proceedings of the 13th International Conference on Solid Waste Technology and Management, Vol 15, pp 239-253, (1997).

[9] T. Sasao, An estimation of the social costs of landfill siting using a choice experiment. Waste Management, Vol 24, pp 753-762, (2004).

[10] B. Sener, M. Süzen, and V. Doyuran, "Landfill site selection by using geographic information systems." Environmental Geology, Vol 49, pp 376388, (2006).

[11] S. Sener, E. Sener, and R. Karagüzel, "Solid waste disposal site selection with GIS and AHP methodology: A case study in Senirkent-Uluborlu (Isparta) Basin, Turkey." Environmental Monitoring and Assessment, Vol 173, (2011).

[12] S. A. Al Raisi2014, msc, landfill suitablity analysis using ahp method and state of heavy metals pollution in selected landfills in Oman, European Scientific Journal, Vol 10, (2014).

[13] S. Zakerian, M. Mokhtari, Evaluation of a Landfill Site Using AHP and TOPSIS Models: A Case Study of Ardakan Landfill, Iran, Avicenna Journal of Environmental Health Engineering, Vol 2, 11-12 (2015).
[14] T.L. Saaty, Decision making with the analytic hierarchy process, Int. J. Services Sciences, Vol 1, No. 1, (2008).

[15] T.L. Saaty, and L.G. Vargas, Models, Methods, Concepts and Applications of the Analytic Hierarchy Process, Boston: Kluwer Academic Publishers, (2000).

[16] Perron-Frobenius, Theorie der Matrizen, Math. Ann., Vol 64, (1907).

[17] J. A. ALONSO, Consistency in the Analytic Hierarchy Process: A NEW APPROACH International Journal of Uncertainty, Fuzziness and Knowledge-Based Systems Vol 14, pp 445-459, (2006) 